\title{
Mutation in the protease cleavage site of GDF9 increases ovulation rate and litter size in heterozygous ewes and causes infertility in homozygous ewes
}

\author{
C. J. H. Souza*1, A. S. McNeilly ${ }^{\dagger}$, M. V. Benavides ${ }^{\ddagger}$ E. O. Melo ${ }^{\S}$ and J. C. F. Moraes* \\ *Embrapa Pecuaria Sul, BR 153 Km 604, Caixa Postal 242, CEP 96400-970, Bage, Brazil. 'MRC Centre for Reproductive Health, University \\ of Edinburgh, 47 Little France Crescent, EH16 4TJ, Edinburgh, UK. "Embrapa LabEx USA, 5601 Sunnyside Avenue, 20705-5141, Beltsville, \\ MD, USA. ${ }^{\S}$ Embrapa Recursos Geneticos e Biotecnologia, PqEB - Av. W5 Norte (final), CEP 70770-917, Brasilia, Brazil.
}

\section{Summary}

\section{Introduction}

Litter size (LS) in sheep is determined mainly by the number of ovulations per oestrous cycle (ovulation rate, OR). Several polymorphisms have been identified to be associated with an increase in both OR and LS. The majority of these polymorphisms are located in genes of the transforming growth factor beta (TGFb) superfamily or its receptor (Juengel et al. 2013). These polymorphisms are most prevalent in the bone morphogenetic protein 15 gene (BMP15) followed by the growth differentiation factor 9 (GDF9) and bone morphogenetic protein receptor type $1 B(B M P R 1 b)$ genes.

Address for correspondence

C. J. H. Souza, Embrapa Pesca e Aquicultura, Quadra 104 Sul, Av. LO 1 , Nro 34, Conj 4, $1^{\circ}$ e $2^{\circ}$ pavimentos, CEP 77020-020, Palmas, Brazil. E-mail: carlos.hoff-souza@embrapa.br

${ }^{1}$ Present address: Embrapa Pesca e Aquicultura, Quadra 104 Sul, Av. LO 1, Nro 34, Conj $4,1^{\circ}$ e $2^{\circ}$ pavimentos, CEP 77020-020, Palmas, Brazil.

Accepted for publication 20 May 2014
The BMP15 mutations, Galway (Hanrahan et al. 2004), Hanna, Inverdale (Galloway et al. 2000), Lacaune (Bodin et al. 2007) and Belclare (Hanrahan et al. 2004), and a deletion in the breed Rasa Aragonesa (Martinez-Royo et al. 2008; Monteagudo et al. 2009) have a phenotype of increased prolificacy in the heterozygous and infertility in the homozygous ewes, whereas the Grivette and Olkuska mutations (Demars et al. 2013) have an additive effect on OR and LS.

Mutations in GDF9, Embrapa (Silva et al. 2011) and G7 (Vage et al. 2013), have an additive effect on OR and LS, whereas the High Fertility (Hanrahan et al. 2004) and Thoka (Nicol et al. 2009) mutations cause increased prolificacy in the heterozygous and infertility in the homozygous ewes.

The BMPR1b Booroola mutation (Mulsant et al. 2001; Souza et al. 2001; Wilson et al. 2001) causes an additive effect on OR and a dominant effect for LS.

The peculiarity of the polymorphisms in the oocytesecreted growth factors GDF9 and BMP15 is that some of 
them have an additive effect on OR and LS, whereas others cause increased OR and LS in the heterozygotes and infertility in the homozygous carriers. This phenotype is probably due to reduction in the activity of the protein or disruption in its translation, processing and secretion (Juengel et al. 2013).

The aim of this work was to describe a novel SNP in GDF9 that was named Vacaria $\left(\right.$ FecG $\left.^{v}\right)$. This polymorphism is a transition from $\mathrm{C}$ to $\mathrm{T}$ at base 943 of the open reading frame (c.943C $>\mathrm{T}$ ) and causes increased OR and LS in heterozygous and infertility in homozygous ewes of the Ile de France breed raised in south Brazil.

\section{Material and methods}

\section{Identification of prolific families}

The databank of the Brazilian Sheep Breeders Association (ARCO) was screened to identify flocks with triplet deliveries from 2005 to 2009. Upon the identification of such flocks, the owners were contacted and the use of hormonal preparations in the ewes investigated. Only flocks that used natural mating were accepted for the study, and the lambing record of each breeding ewe was obtained and a blood sample collected. Once the prolific families with recurrent multiple lambing were identified, an investigation was made on the progeny of each ewe with a history of triplet birth delivery. All animal procedures were approved by the Local Ethics Committee prior to the initiation of the studies.

\section{DNA extraction, Booroola and Embrapa genotyping}

Genomic DNA was extracted from buffy coat of ewes with at least one triplet delivery record using the salting out method (Miller et al. 1988). The DNA was quantified by spectrophotometry (Nanodrop 2000; Thermo Fisher Scientific, Inc.), and its integrity verified by agarose gel electrophoresis. Ewes with recurrent multiple deliveries were genotyped by PCR-RFLP for the presence of the Booroola (Wilson et al. 2001) and Embrapa mutations (Silva et al. 2011), two mutations affecting OR so far demonstrated to be segregating in Brazilian flocks (Souza et al. 2009). All tested females were non-carriers of either mutations and provided genomic DNA to sequence BMP15 and GDF9 to investigate the presence of polymorphisms that could justify their prolificacy.

\section{Resequencing of GDF9 and BMP15}

Primers were designed based on the genomic GenBank sequence of sheep GDF9 (AF078545) and BMP15 (AF236078 and AF236079). The designed primers (Table 1), homologous to the intronic regions flanking exons 1 and 2 of both genes, were used in PCR amplification and sequencing.
Table 1 Oligonucleotide primers used for PCR and sequencing BMP15 and GDF9.

\begin{tabular}{lll}
\hline Gene & Oligonucleotide & Sequence 5' $^{\prime}$ 3' $^{\prime}$ \\
\hline BMP15 & BX1S & GCGTTATCCTTTGGGCTTTT \\
BMP15 & BX1A & GCAATGTGAAGCCTGACAGA \\
BMP15 & BX2S & GCTTTGCTCTTGTTCCCTCTT \\
BMP15 & BX2A & TGCACCTTTGCCGTCAC \\
BMP15 & B5F & CATCAGCTTCACCTAACTCATTC \\
BMP15 & B7R & GAACTCAAGAACCTCACTACC \\
GDF9 & GX1S & CGAGGCTCTTCCTGGTTTTT \\
GDF9 & GX1A & CAGCACTCTTCCCAGGTTTT \\
GDF9 & GX2S & GGGGAGAAAAGGGACAGAAG \\
GDF9 & GX2A & TACACTGGCCAGGACACTCA \\
GDF9 & G11R & GGAGAGTGCCAGCTCTGAATT \\
GDF9 & G15R & CGGAAGACCAGCTGCAGCAT \\
GDF9 & G16F & AATGGATGGAGATTGATGTGACG \\
GDF9 & G19F & GAACGACACAAGTGCTCAGG \\
\hline
\end{tabular}

For sequencing of the GDF9 coding region, PCRs were performed using at least $100 \mathrm{ng}$ of genomic DNA with oligos GX1S and GX2A, with high-fidelity Pfu polymerase (Herculase II Fusion Enzyme, Stratagene Europe) as instructed by the manufacturer. PCR conditions were as follows: denaturation at $95^{\circ} \mathrm{C}$ for $2 \mathrm{~min}$ followed by 30 cycles of denaturation $95{ }^{\circ} \mathrm{C}$ for $20 \mathrm{~s}$, annealing at $59{ }^{\circ} \mathrm{C}$ for $20 \mathrm{~s}$, extension at $72{ }^{\circ} \mathrm{C}$ for $90 \mathrm{~s}$ and the final extension at $72{ }^{\circ} \mathrm{C}$ for $3 \mathrm{~min}$, which generated an amplicon of 2609 base pairs (bp). The PCR product was applied to $1 \%$ agarose gel, and the corresponding amplicon was cut from the gel and purified using Wizard SV Gel and PCR Clean-Up System kit (Promega), according to the manufacturer's instructions. The purified amplicon was quantified using a NanoDrop spectrophotometer, and the preparations along with oligos GX1S, GX1A, GX2S, G11R, G15F, G16F, G19F and GX2A were sequenced using Big Dye cycle sequencing chemistry 3.1 and an ABI PRISM 3100 Genetic Analyzer sequencer (Applied Biosystems) by the MRC Human Genetics Unit sequencing service.

BMP15 sequencing was performed with two PCRs for each proband using at least $100 \mathrm{ng}$ of genomic DNA each and BX1S and BX1A oligos for exon 1 and BX2S and BX2A for exon 2. PCR conditions were as follows: denaturation at $95^{\circ} \mathrm{C}$ for $2 \mathrm{~min}$ followed by 30 cycles of denaturation $95{ }^{\circ} \mathrm{C}$ for $20 \mathrm{~s}$, annealing at $59{ }^{\circ} \mathrm{C}$ for $20 \mathrm{~s}$, extension at $72{ }^{\circ} \mathrm{C}$ for $90 \mathrm{~s}$ and the final extension at $72{ }^{\circ} \mathrm{C}$ for $3 \mathrm{~min}$, which generated 485 and 901 base pairs amplicons for exons 1 and 2 respectively. The purified amplicons were quantified using a NanoDrop spectrophotometer, and the preparations along with oligos BX1S and BX1A oligos for exon 1 and BX2S, B5F, B7R and BX2A for exon 2 were also sent to the sequencing service.

The chromatograms obtained were evaluated for their quality using 4PEAKS software (mekentosj.com, the Netherlands Cancer Institute). The sequences generated were aligned using CLC SEQUENCE VIEWER 6.3 software (www.clcbio.com), and the presence of polymorphisms was investigated. 
Bioinformatic tools available on the Internet were used to predict the effect of the amino acid changes on protein structure and function. PANTHER 8.1 software (http:// www.pantherdb.org/tools/csnpScoreForm.jsp) calculates the subPSEC score (position of substitution and particular evolutionary conservation) based on an alignment of evolutionarily related proteins (Thomas \& Kejariwal 2004). SubPSEC scores are continuous values of 0 (neutral) to about -10 (most likely to be harmful), and SNPs scoring lower than -3 are predicted to have a deleterious effect on protein function. PROVEAN 1.1 online software (http://prov ean.jcvi.org/seq_submit.php) also predicts whether a protein sequence variation affects protein function based on alignment of clusters of closely related sequences generating a PROVEAN score. If the PROVEAN score is equal to or less than a predefined threshold (e.g. -2.5), the protein variant is predicted to have a deleterious effect (Choi et al. 2012).

\section{Genotyping of the Vacaria SNP}

A rapid test for genotyping the Vacaria mutation based on the methodology tetra-primer ARMS PCR was developed (Ye et al. 2001). Specific primers were designed with PRIMER 1 online software (http://primer1.soton.ac.uk/ primer1.html) using the GDF9 exon 2 sequence as a template. PCR amplification was performed in reactions containing $100 \mathrm{ng}$ of genomic DNA, $2.5 \mu \mathrm{l}$ of $10 \times$ buffer $(100 \mathrm{~mm}$ Tris-HCl, pH 8.5; $500 \mathrm{~mm} \mathrm{KCl),} 200 \mu \mathrm{m}$ of dNTPs, $1.5 \mathrm{~mm}$ $\mathrm{MgCl}_{2}, 25$ pм of inner primers: FIP (C allele) $5^{\prime}$-AGCTGCT GAGGGTGTAAGATCGTACC- $3^{\prime}$ and RIP (T allele) 5'-GCACT CTCCTGGTCTCTGCGGTGCCA-3', 2.5 pm of the outer primers: FOP 5'-ACTCTTCTCGTAGCGCCCTCACTGCTTT-3' and ROP 5'-GGATGATGTTCTGCACCATGGTGTGAA-3', 1 unit of Taq DNA polymerase (Ludwig Biotecnologia Ltda) and sterile water to bring the total volume to $25 \mu \mathrm{l}$. PCR conditions were similar to those previously described. The resulting amplicons were resolved in a $1.5 \%$ agarose gel, with the size of 300 base pairs for the $C$ allele $(\mathrm{N}), 200 \mathrm{bp}$ for the variant $T$ allele $(\mathrm{V})$ and $448 \mathrm{bp}$ for the control outer primers.

This test was used to genotype the Vacaria SNP in 171 animals participating in a regional farm show to estimate the allele frequency in the Brazilian Ile de France pedigree flock. The test was also used to genotype 297 ewes with at least two lambing records from four elite breeding flocks segregating the Vacaria allele and to genotype over 200 animals to establish an experimental flock segregating the polymorphism.

\section{Laparoscopic examination to evaluate OR}

The presence of the Vacaria SNP was observed only as heterozygotes in the breeding flocks genotyped. To evaluate its effect on the OR in a controlled situation, an experimental flock was initiated in the 2010 breeding season. Corriedale cross-ewes were mated with an Ile de France Vacaria heterozygous $(V N)$ ram; the resulting female progeny of a total 86 ewes segregating the Vacaria SNP were also successively mated with $V N$ rams for three breeding seasons.

The ewe lambs in the first breeding season received an intravaginal sponge with $60 \mathrm{mg}$ of MAP for 14 days. After sponge withdrawal, teasers with crayon harnesses were introduced to detect oestrus (day 0) and, on day 7, the animals were subjected to a laparoscopic examination to evaluate OR (Thimonier et al. 1969). After laparoscopy, a prostaglandin F2 alpha analogue (PG, Cloprostenol $125 \mu \mathrm{g}$, Ciosin, MSD Saude Animal) was injected and the animals re-examined 10 days later. The cycle of exams was repeated up to three times prior to mating. At the subsequent breeding seasons, the ewes were submitted to laparoscopy to evaluate the OR, 7 days after oestrus induced by ram effect with $10 \%$ teasers with harnesses or 10 days after a PG injection. Following the examination, the animals received a PG injection and were re-examined 10 days after. At each breeding season, the ewes had up to three laparoscopies and the flock was then mated with a $V N$ ram.

\section{Analysis of ovarian follicular population}

Three ewe lambs from each genotype of 8 months of age, weighing at least 28 kilos received an intravaginal sponge with $60 \mathrm{mg}$ of MAP for 14 days. After sponge withdrawal, a teaser with crayon harness was introduced to detect oestrus (day 0), and on day 10, the animals received a PG injection. The Vacaria homozygous $(V V)$ ewe lambs did not show oestrus behaviour, but received a PG injection at the same time as the cycling animals. The animals were sacrificed $36 \mathrm{~h}$ after PG injection, when the ovaries were recovered for analysis of the follicular population during the follicular phase.

Ovaries were recovered and examined, and all large antral follicles dissected. The number and size of each follicle were recorded.

\section{Histology}

Tissues were immersed in Bouin's fixative for $6 \mathrm{~h}$, transferred to $70 \%$ ethanol, then dehydrated and embedded in paraffin wax. Five-micron sections were cut, floated onto slides, dried at $50{ }^{\circ} \mathrm{C}$ for several hours then dewaxed and rehydrated. Sections were stained with haematoxylin and eosin, dehydrated and mounted with coverslips. Images were photographed using a Zeiss Stemi 2000C stereomicroscope (Carl Zeiss) with an ERc5s camera (Carl Zeiss) and a Leica DM2500 microscope (Leica Microsystems CMS $\mathrm{GmbH}$ ) with a Leica DFC500 camera (Leica Microsystems Ltd). 


\section{Statistical analysis}

Analyses of variance and means comparison were performed with the software $\mathrm{R}$ using the package Psych (Version 1.3.2) and the lattice package (Version 0.20.5) for illustration (http://www.r-project.org/).

\section{Results}

\section{Identification of prolific flocks and ewes}

Seven prolific families were identified in the Ile de France breed, which showed a prevalence of $0.38 \%$ triplet delivery on 20229 recorded matings in the Brazilian Sheep Breeders Association databank. From these prolific families, 25 ewes with a history of delivering at least one triplet and recurrent multiple delivery were selected for genetic screening. These ewes were genotyped for the Booroola and Embrapa polymorphisms, which are the two SNPs affecting OR so far demonstrated to be segregating in Brazilian flocks (Souza et al. 2009). All tested females were non-carriers of both Booroola and Embrapa mutations, which justified the sequencing of the GDF9 and BMP15 genomic DNA to investigate the presence of known polymorphisms or the existence of new SNPs that could explain their increased prolificacy.

\section{GDF9 and BMP15 SNPs}

The resequencing of GDF9 revealed a novel non-synonymous mutation in two of the 25 investigated prolific ewes (Table 2). The mutation is a transition from $\mathrm{C}$ to $\mathrm{T}$ at base 943 of the open reading frame (c.943C $>$ T), resulting in a non-conservative change of amino acid residue 315 of the proregion from an arginine (basic, polar) to a cysteine (neutral, polar). This change is located in the cleavage site of the proprotein convertase subtilisin kexin (PCSK) proteases, which are responsible for separating the mature

Table 2 Frequency of GDF9 polymorphisms observed in Brazilian prolific lle de France ewes.

\begin{tabular}{lllll}
\hline Polymorphism & $\begin{array}{l}\text { Wild } \\
\text { type (\%) }\end{array}$ & $\begin{array}{l}\text { Heterozygote } \\
(\%)\end{array}$ & $\begin{array}{l}\text { Mutant } \\
(\%)\end{array}$ & $\begin{array}{l}\text { Mutant } \\
\text { allele }\end{array}$ \\
\hline $\begin{array}{l}\text { G1:c.260G>A } \\
\text { (p.Arg87His) }\end{array}$ & 68 & 32 & 0 & 0.16 \\
$\begin{array}{l}\text { G2:c.471C>T } \\
\text { (p.Val157Val) }\end{array}$ & 76 & 24 & 0 & 0.12 \\
$\begin{array}{l}\text { G3:c.477G>A } \\
\text { (p.Leu159Leu) }\end{array}$ & 16 & 72 & 12 & 0.48 \\
$\begin{array}{l}\text { G4:c.721G>A } \\
\text { (p.Glu241Lys) }\end{array}$ & 72 & 28 & 0 & 0.14 \\
$\begin{array}{l}\text { Vacaria:c943C>T } \\
\text { (p.Arg315Cys) }\end{array}$ & 92 & 8 & 0 & 0.04 \\
$\begin{array}{l}\text { G5:c.978A>G } \\
\text { (p.Glu326Glu) }\end{array}$ & 32 & 68 & 0 & 0.34 \\
$\begin{array}{l}\text { G6:c.994G>A } \\
\text { (p.Val332Val) }\end{array}$ & 28 & 72 & 0 & 0.36 \\
\hline
\end{tabular}

domain from the proprotein, a step deemed essential for GDF9 biological activity (Paulini \& Melo 2011). This new allele was named Vacaria $\left(\right.$ FecG $\left.^{v}\right)$ after the city where the first flocks with this polymorphism were located.

The Vacaria (p.Arg315Cys) mutation was predicted to have a deleterious effect on protein function with a PANTHER subPSEC score of -4.767 (cut off $=-3$ ) and PROVEAN score of -4.667 (cut off $=-2.5$ ). The arginine at residue 315 in sheep GDF9 is highly conserved among vertebrates ranging from fish to mammals (Fig. 1), and the Vacaria mutation disrupts the PCSK cleavage site RHRR to a CHRR, which is predicted to abolish the production of the mature protein according to PROP 1.0 software analysis (http:// www.cbs.dtu.dk/services/ProP/).

Six other polymorphisms were detected in the GDF9 sequence analysis (Table 2), and all of them were predicted to have no effect on protein function by the PANTHER and PROVEAN softwares. These polymorphisms (G1, G2, G3, G4, G5, G6) have been previously reported as without association with increased OR/LS or sterility (Hanrahan et al. 2004).

The BMP15 resequencing revealed the presence of a deletion at position 28-30 of the coding region, resulting in a deletion of a leucine at residue 10 of the prodomain. This deletion has been previously reported as not associated with any reproductive phenotype (Galloway et al. 2000; Hanrahan et al. 2004). The BMP15:c.28_30delCTT was observed with an allele frequency of 0.61 in $41 \%$ of heterozygotes and $41 \%$ of homozygous mutant ewes.

\section{Frequency of the Vacaria SNP in the Brazilian flock}

In two consecutive years, all Ile de France animals participating in the major regional farm show were genotyped for the $\mathrm{FecG}^{V}$ allele. Genotyping using genomic DNA from 171 sheep showed that 14\% of the animals were heterozygous and indicated that the Vacaria mutation was segregating in six elite breeding flocks. The majority of the sampled animals were young sires and would contribute to the maintenance/spreading of the SNP in the commercial flocks.

Four elite breeding flocks segregating the Vacaria SNP, comprising a total of 297 females with lambing records of at least two breeding seasons, had a prevalence of $19 \%$ heterozygous $(V N)$ ewes. The $V N$ ewes had increased LS $(P<0.001)$ of $1.61 \pm 0.07$, whereas their contemporary wild-type females $(\mathrm{NN})$ averaged $1.29 \pm 0.03$.

\section{Evaluation of OR in an experimental flock segregating the Vacaria SNP}

The OR was investigated by exploratory laparoscopy in 86 ewes with distinct genotypes at ages of 8,20 and 32 months, ranging from one to eight laparoscopies per female (up to three exams prior to each breeding season). A total of 214 laparoscopies were performed, resulting in 188 
R315C

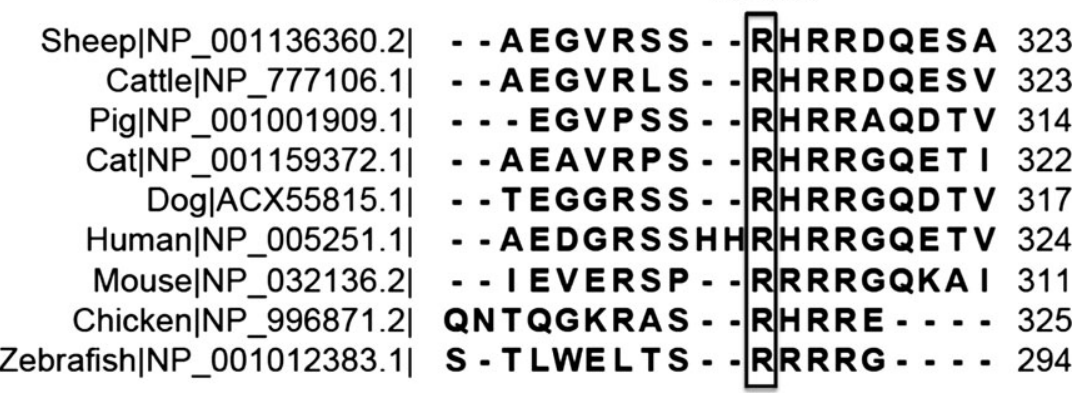

Figure 1 GDF9 multispecies alignment in the region of the Vacaria SNP.

Table 3 Average ovulation rate \pm SE of the ewes examined prior to the first three breeding seasons (number of exams).

\begin{tabular}{llll}
\hline $\begin{array}{l}\text { Age } \\
\text { group } \\
\text { (months) }\end{array}$ & $N N$ & VN & Total \\
\hline 8 & $1.17 \pm 0.38(41)$ & $1.71 \pm 0.58(51)$ & $1.47 \pm 0.06(92)$ \\
20 & $1.24 \pm 0.44(33)$ & $2.40 \pm 0.85(43)$ & $1.89 \pm 0.10(76)$ \\
32 & $1.30 \pm 0.48(10)$ & $2.50 \pm 0.71(10)$ & $1.90 \pm 0.19(20)$ \\
Total & $1.21 \pm 0.05(84)$ & $2.07 \pm 0.08(104)$ & $(188)$ \\
\hline
\end{tabular}

exams where the presence of corpora lutea was identified, and these were considered for analysis.

The means and standard errors (SE) of OR observed in the three ages and genotypes are presented in Table 3. The analysis of variance indicated that age, genotype and their interaction were significant for OR $(P<0.001)$. A second model of analysis of variance that included the error of repetitions within the same individual showed that only the genotype significantly affected the OR $(P<0.001)$. The ovulation frequencies between the genotypes can be observed in Fig. 2, considering the three age groups when the animals were evaluated. The Vacaria SNP caused an overall increase of $70 \%$ in the OR in heterozygotes when compared with $N N$ half-sib ewes under the same environment.

Reproductive tract abnormalities and infertility correlate with homozygosis for Vacaria mutation

To confirm the bioinformatics prediction that the Vacaria SNP would disrupt the production of biologically active GDF9, the reproductive tract of nine ewe lambs of the three genotypes was recovered and examined during the late follicular phase. The $V V$ females had uterine and ovarian hypoplasia (Fig. 3). The 'streak' ovaries of the $V V$ animals

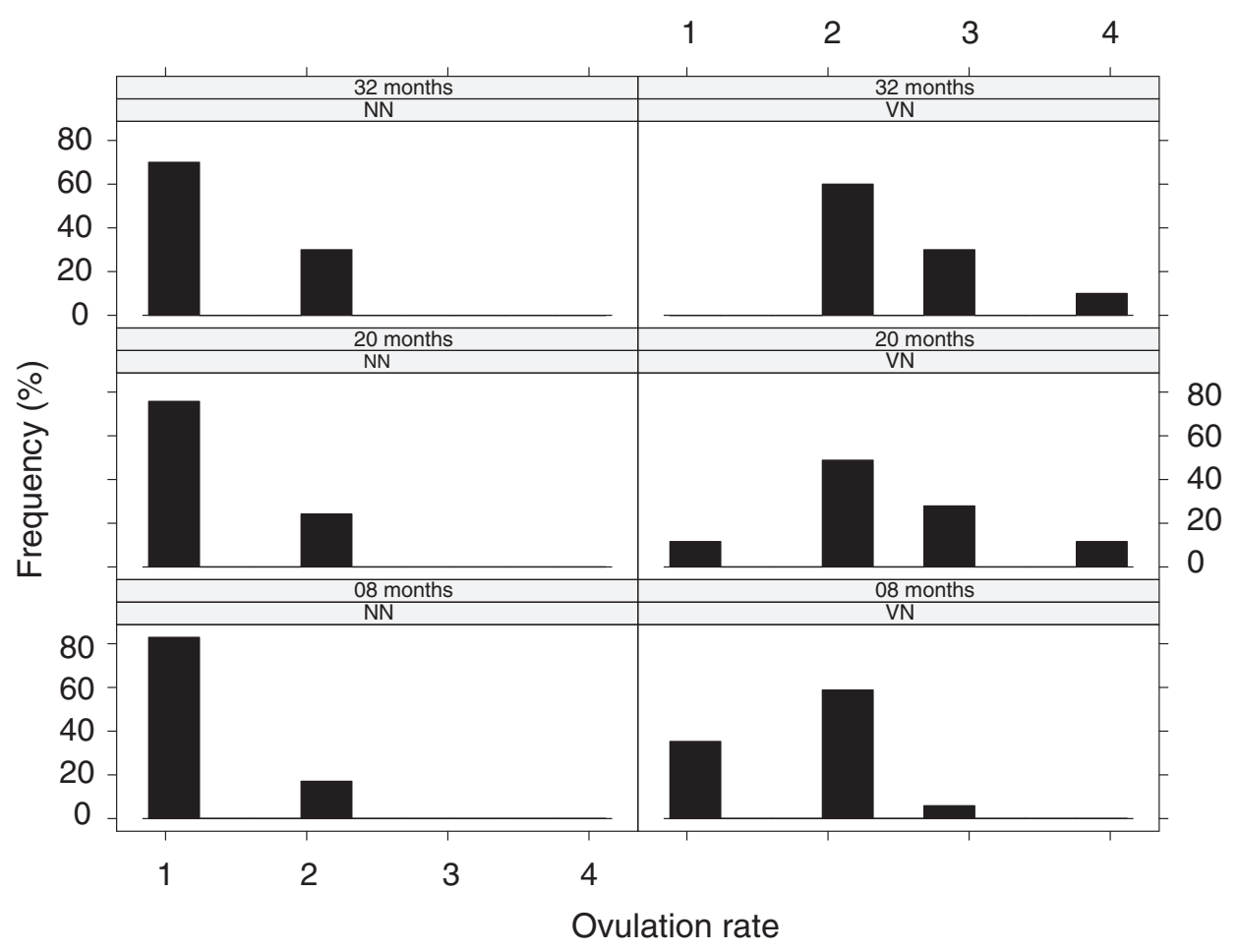

Figure 2 Type of ovulation by genotype in the first three breeding seasons at 8, 20 and 32 months of age. 

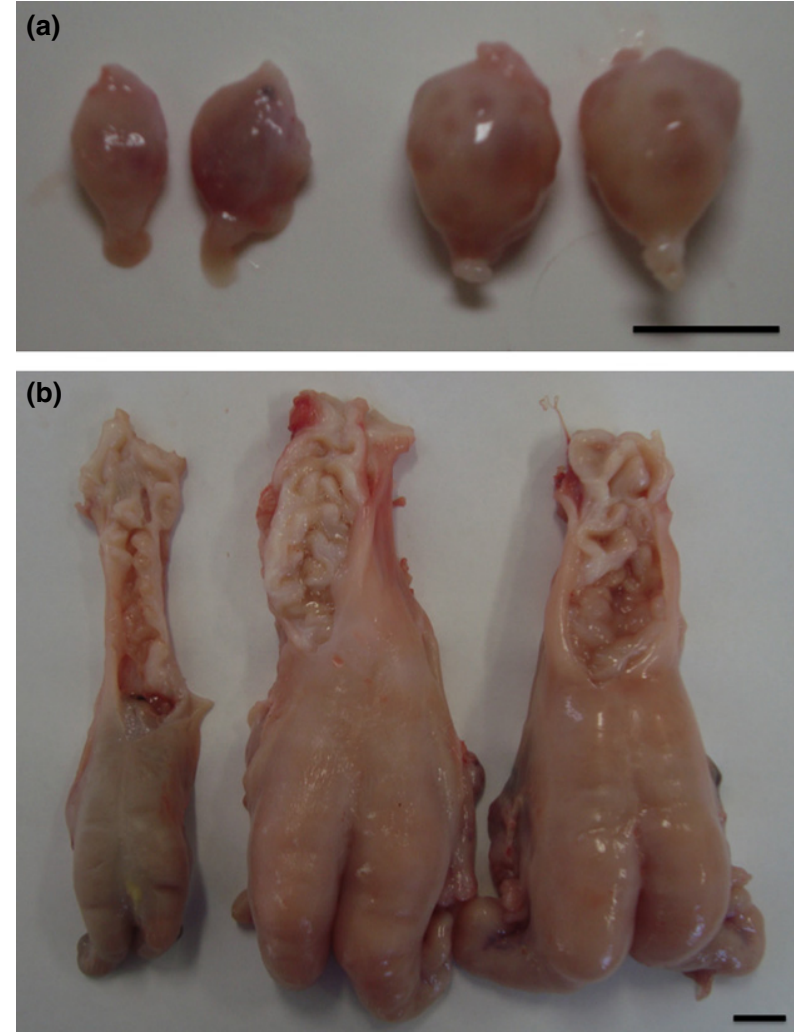

Figure 3 Reproductive tracts gross morphology. (a) Ovaries from a $V V$ (left) and a $N N$ (right) ewe lamb at 8 months of age. Notice the size difference between the genotypes and the absence of large antral follicles in the mutant ovary. (b) Uterus from a $V V$ (left), $V N$ (middle) and a $N N$ ewe lamb (right) showing a small rudimentary uterus in the $V V$ animal and organs with normal development in the other genotypes. Scale bar represents $1 \mathrm{~cm}$.

were devoid of large antral follicles and were fixed for histological examination. The ovaries from the remaining females presented a normal morphological appearance and were dissected. The size and number of large antral follicles dissected were recorded. The follicular population greater than $3 \mathrm{~mm}$ in $V N$ females was $3.3 \pm 0.4$ follicles with the diameter averaging $4.9 \pm 0.6 \mathrm{~mm}$, whereas the $N N$ ewes had an average of $2.0 \pm 1.2$ follicles with a mean diameter of $6.7 \pm 0.8 \mathrm{~mm}$. This suggests that the $V N$ dominant follicles would ovulate at a smaller diameter, although that remains to be confirmed in a larger number of animals.

The hypoplastic ovaries from $V V$ ewe lambs contained large numbers of primordial follicles and developing follicles up to small antral stage, with a diameter of up to $2 \mathrm{~mm}$ (Fig. 4). Most of the developing follicles had oocytes of abnormal appearance and layers of asymmetrically arranged granulosa cells. At higher magnification, many follicles appeared to be in the process of collapsing or had totally collapsed. The granulosa cells from collapsed oocyte follicles seemed to arrange themselves in clusters or nodular structures of varying sizes generally found in the inner cortex of the ovary.

\section{Discussion}

In the present study, we describe a novel GDF9 SNP (c.943C $>$ T) that causes increased OR/LS in the heterozygous females and hypoplasia of uterus and ovaries accompanied of impaired follicle development in the homozygous ewes. The Vacaria polymorphism provokes a residue change (p.Arg315Cys) in the cleavage site for the PCSK proteases, highlighting the necessity of the proteolytic processing for the biological activity of GDF9. Other mutations in sheep that block GDF9 activity, such as the High Fertility mutation (p.Ser395Phe), predicted to disrupt interaction with a type 1 receptor of the TGFb family, and the Thoka mutation (p.Ser427Arg), which is thought to disturb binding to the type 2 receptor (Juengel et al. 2013), also result in a phenotype of increased OR/LS in heterozygous ewes and infertility linked to hypoplasia of ovary and uterus in homozygous females. Adult ewes immunised against GDF9 stop having oestrous cycles, with follicular development arrested beyond the primary stage in most animals (Juengel et al. 2002).

GDF9 is secreted in follicular fluid as proprotein and mature forms in primates and humans (Duffy 2003; Gode et al. 2011), and increased concentration of the human GDF9 mature form in follicular fluid is significantly correlated with nuclear maturation of oocytes and quality of embryos produced in vitro (Gode et al. 2011). In sheep, GDF9 is present in follicular fluid at significant levels as unprocessed premature forms (McNatty et al. 2006) but is secreted in the mature form in media incubated with denuded oocytes from antral follicles (Lin et al. 2012).

Post-translational processing is important for the secretion of biologically active GDF9. During this process, the signal peptide is removed and the proprotein undergoes dimerisation. As processing proceeds, specific PCSK proteolytic enzymes cleave the dimerised proproteins at the conserved cleavage site (RHRR). The PCSK cleavage liberates the biologically active dimeric mature protein to be secreted by the cell (Paulini \& Melo 2011).

The ovarian hypoplasia observed in the Vacaria homozygotes was also seen in other sheep SNP inactivating GDF9 (Hanrahan et al. 2004; Nicol et al. 2009). The ovarian morphology with development of small antral follicles observed in this study is similar to what was reported in ewes homozygous for the High Fertility SNP (McNatty et al. 2005) and not as severe as that reported for the Thoka homozygous ewes, where the follicle development beyond secondary stage is abolished (Nicol et al. 2009). The clusters of granulosa-like cells that persist after the collapse of the oocyte in $V V$ ewes were also observed in sheep homozygous of other polymorphisms with a similar phenotype (Pitman et al. 2012); however, the fate of these cells remain to be elucidated.

The uterine hypoplasia observed in the Vacaria homozygous ewe lambs is similar to that observed in the 

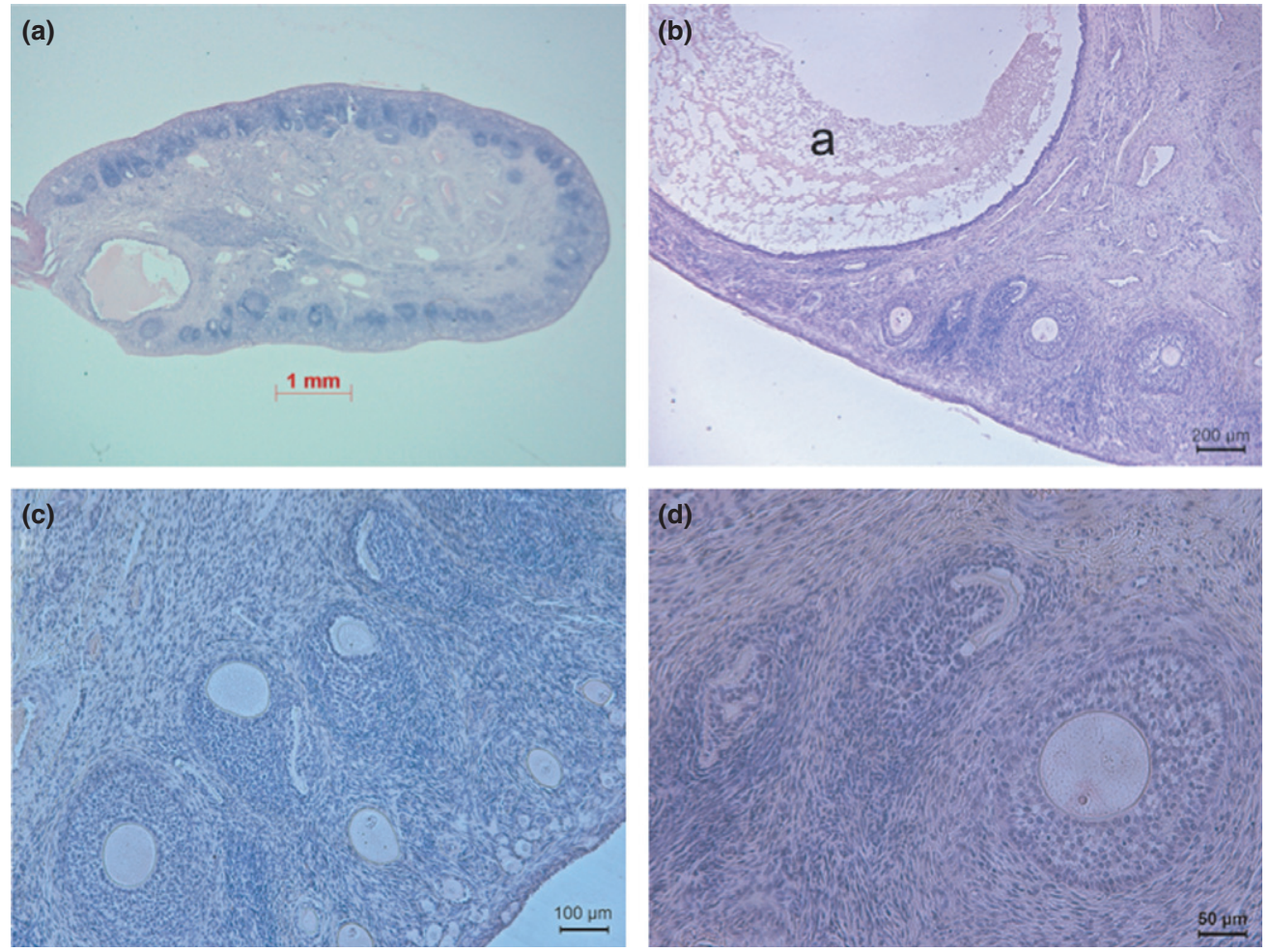

Figure 4 Morphology of the 'streak' ovaries from $V V$ ewe lambs. (a) Mid section of an ovary, with the presence of an antral follicle and clusters of granulosa-like cells that remain after the collapse of the oocytes in the inner cortical region. (b) An antral follicle (a) and developing secondary follicles with oocytes in various degree of atresia. (c) Follicles in the process of oocyte collapsing and the cluster of granulosa-like cells that remain after the oocyte demise. (d) Larger magnification of the follicles in B showing a secondary follicle with vacuolated granulosa layer and adjacent follicles with collapsed oocytes.

Inverdale (Davis et al. 1992; Hayashi et al. 2008) and Thoka (Nicol et al. 2009) homozygous ewes. This suggests that the uterotrophic factor secreted by the ovary in the neonate period (Carpenter et al. 2003) is produced by the developing follicles that are inhibited by the inadequate processing of mature GDF9 in the $V V$ ewe lambs.

In conclusion, the present study validates the strategy to identify prolific families and use of candidate genes to investigate causative DNA polymorphisms. The Vacaria SNP (p.Arg315Cys) causes increased OR/LS in the heterozygote and infertility due to ovarian and uterine hypoplasia in the homozygote ewes. This phenotype is probably due to the disruption of the PCSK cleavage site of the GDF9 proprotein, preventing the conversion into dimeric mature GDF9 that is the biologically active form of the protein. This newly characterised SNP can be used to improve selection for prolificacy of dams and also as a biological model to investigate the fate of the follicular cells that remain after the oocyte demise in VV ewes.

\section{Acknowledgements}

We are grateful to Dr Maria Gabriela Tavares Rheingantz and Mr Luis Augusto Cruz for their help with histology.

\section{Declaration of interest}

The authors declare that there is no conflict of interest that could be perceived as prejudicing the impartiality of the research reported.

\section{Funding}

This research was supported by Conselho Nacional de Desenvolvimento Científico e Tecnológico - CNPq (473297/ 2007-8), Coordenação de Aperfeiçoamento de Pessoal de Nível Superior - CAPES (0064/09-2) and Empresa Brasileira de Pesquisa Agropecuária - Embrapa (03.08.06.035 and 02.08.02.003).

\section{References}

Bodin L., Di Pasquale E., Fabre S., Bontoux M., Monget P., Persani L. \& Mulsant P. (2007) A novel mutation in the bone morphogenetic protein 15 gene causing defective protein secretion is associated with both increased ovulation rate and sterility in Lacaune sheep. Endocrinology 148, 393-400.

Carpenter K.D., Hayashi K. \& Spencer T.E. (2003) Ovarian regulation of endometrial gland morphogenesis and activin- 
follistatin system in the neonatal ovine uterus. Biology of Reproduction 69, 851-60.

Choi Y., Sims G.E., Murphy S., Miller J.R. \& Chan A.P. (2012) Predicting the functional effect of amino acid substitutions and indels. PLoS One 7, e46688.

Davis G.H., McEwan J.C., Fennessy P.F., Dodds K.G., McNatty K.P. \& O W.S. (1992) Infertility due to bilateral ovarian hypoplasia in sheep homozygous (FecXI FecXI) for the Inverdale prolificacy gene located on the X chromosome. Biology of Reproduction 46, 636-40.

Demars J., Fabre S., Sarry J. et al. (2013) Genome-wide association studies identify two novel BMP15 mutations responsible for an atypical hyperprolificacy phenotype in sheep. PLoS Genetics 9, e1003482.

Duffy D.M. (2003) Growth differentiation factor-9 is expressed by the primate follicle throughout the periovulatory interval. Biology of Reproduction 69, 725-32.

Galloway S.M., McNatty K.P., Cambridge L.M. et al. (2000) Mutations in an oocyte-derived growth factor gene (BMP15) cause increased ovulation rate and infertility in a dosagesensitive manner. Nature Genetics 25, 279-83.

Gode F., Gulekli B., Dogan E., Korhan P., Dogan S., Bige O., Cimrin D. \& Atabey N. (2011) Influence of follicular fluid GDF9 and BMP15 on embryo quality. Fertility and Sterility 95, 2274-8.

Hanrahan J.P., Gregan S.M., Mulsant P., Mullen M., Davis G.H., Powell R. \& Galloway S.M. (2004) Mutations in the genes for oocyte-derived growth factors GDF9 and BMP15 are associated with both increased ovulation rate and sterility in Cambridge and Belclare sheep (Ovis aries). Biology of Reproduction 70, 900-9.

Hayashi K., O’Connell A.R., Juengel J.L., McNatty K.P., Davis G.H., Bazer F.W. \& Spencer T.E. (2008) Postnatal uterine development in Inverdale ewe lambs. Reproduction 135, 357-65.

Juengel J.L., Hudson N.L., Heath D.A. et al. (2002) Growth differentiation factor 9 and bone morphogenetic protein 15 are essential for ovarian follicular development in sheep. Biology of Reproduction 67, 1777-89.

Juengel J.L., Davis G.H. \& McNatty K.P. (2013) Using sheep lines with mutations in single genes to better understand ovarian function. Reproduction 146, R111-23.

Lin J.Y., Pitman-Crawford J.L., Bibby A.H., Hudson N.L., McIntosh C.J., Juengel J.L. \& McNatty K.P. (2012) Effects of species differences on oocyte regulation of granulosa cell function. Reproduction 144, 557-67.

Martinez-Royo A., Jurado J.J., Smulders J.P. et al. (2008) A deletion in the bone morphogenetic protein 15 gene causes sterility and increased prolificacy in Rasa Aragonesa sheep. Animal Genetics 39, 294-7.

McNatty K.P., Galloway S.M., Wilson T. et al. (2005) Physiological effects of major genes affecting ovulation rate in sheep. Genetics, Selection, Evolution 37(Suppl 1), S25-38.

McNatty K.P., Lawrence S., Groome N.P., Meerasahib M.F., Hudson N.L., Whiting L., Heath D.A. \& Juengel J.L. (2006) Meat and Livestock Association Plenary Lecture 2005. Oocyte signalling molecules and their effects on reproduction in ruminants. Reproduction, Fertility, and Development 18, 403-12.
Miller S.A., Dykes D.D. \& Polesky H.F. (1988) A simple salting out procedure for extracting DNA from human nucleated cells. Nucleic Acids Research 16, 1215.

Monteagudo L.V., Ponz R., Tejedor M.T., Lavina A. \& Sierra I. (2009) A 17 bp deletion in the bone morphogenetic protein 15 (BMP15) gene is associated to increased prolificacy in the Rasa Aragonesa sheep breed. Animal Reproduction Science 110, 139-46.

Mulsant P., Lecerf F., Fabre S. et al. (2001) Mutation in bone morphogenetic protein receptor-IB is associated with increased ovulation rate in Booroola Merino ewes. Proceedings of the National Academy of Sciences of the United States of America 98, 5104-9.

Nicol L., Bishop S.C., Pong-Wong R., Bendixen C., Holm L.E., Rhind S.M. \& McNeilly A.S. (2009) Homozygosity for a single base-pair mutation in the oocyte-specific GDF9 gene results in sterility in Thoka sheep. Reproduction 138, 921-33.

Paulini F. \& Melo E.O. (2011) The role of oocyte-secreted factors GDF9 and BMP15 in follicular development and oogenesis. Reproduction in Domestic Animals 46, 354-61.

Pitman J.L., McNeilly A.S., McNeilly J.R., Hays L.E., Bagby G.C. Jr, Sawyer H.R. \& McNatty K.P. (2012) The fate of granulosa cells following premature oocyte loss and the development of ovarian cancers. International Journal of Developmental Biology 56, 949-58.

Silva B.D., Castro E.A., Souza C.J. et al. (2011) A new polymorphism in the growth and differentiation factor 9 (GDF9) gene is associated with increased ovulation rate and prolificacy in homozygous sheep. Animal Genetics 42, 89-92.

Souza C.J., MacDougall C., Campbell B.K., McNeilly A.S. \& Baird D.T. (2001) The Booroola $(F e c B)$ phenotype is associated with a mutation in the bone morphogenetic receptor type $1 B$ (BMPR1B) gene. Journal of Endocrinology 169, R1-6.

Souza C.J.H., Melo E.O. \& Moraes J.C.F. (2009) Genetics of prolificacy and its application to sheep production. Congresso Brasileiro de Reprodução Animal 18, 163-6.

Thimonier J., Mauléon P., Bézard J., Reviers M.-M.D.E. \& Cornu C. (1969) Variations saisonnières du comportement d'œestrus et des activités ovarienne et hypophysaire chez les ovins. Annales De Biologie Animale, Biochimie, Biophysique 9, 233-50.

Thomas P.D. \& Kejariwal A. (2004) Coding single-nucleotide polymorphisms associated with complex vs. Mendelian disease: evolutionary evidence for differences in molecular effects. Proceedings of the National Academy of Sciences of the United States of America 101, 15398-403.

Vage D.I., Husdal M., Kent M.P., Klemetsdal G. \& Boman I.A. (2013) A missense mutation in growth differentiation factor 9 (GDF9) is strongly associated with litter size in sheep. BMC Genetics 14, 1 .

Wilson T., Wu X.Y., Juengel J.L. et al. (2001) Highly prolific Booroola sheep have a mutation in the intracellular kinase domain of bone morphogenetic protein IB receptor $(A L K-6)$ that is expressed in both oocytes and granulosa cells. Biology of Reproduction 64, 1225-35.

Ye S., Dhillon S., Ke X., Collins A.R. \& Day I.N. (2001) An efficient procedure for genotyping single nucleotide polymorphisms. Nucleic Acids Research 29, E88. 